\title{
Effects of copper oxide nanoparticles on developing zebrafish embryos and larvae
}

\author{
This article was published in the following Dove Press journal: \\ International Journal of Nanomedicine \\ 7 March 2016 \\ Number of times this article has been viewed
}

\section{Yan Sun \\ Gong Zhang \\ Zizi He \\ Yajie Wang \\ Jianlin Cui \\ Yuhao Li}

Department of Pathology, Key Laboratory of Tumor Microenvironment and Neurovascular Regulation, Nankai University School of Medicine, Tianjin, People's Republic of China
Correspondence: Jianlin Cui; Yuhao Li Department of Pathology, Key Laboratory of Tumor Microenvironment and Neurovascular Regulation, Nankai University School of Medicine, 94 Weijin Road, Tianjin 30007I, People's Republic of China

Tel +8622 23502554

Fax +862223502554

Email cuijianlin@nankai.edu.cn; liyuhao@nankai.edu.cn

\begin{abstract}
Copper oxide nanoparticles (CuO NPs) are used for a variety of purposes in a wide range of commercially available products. Some $\mathrm{CuO}$ NPs probably end up in the aquatic systems, thus raising concerns about aqueous exposure toxicity, and the impact of CuO NPs on liver development and neuronal differentiation remains unclear. In this study, particles were characterized using Fourier transform infrared spectra, scanning electron microscopy, and transmission electron microscopy. Zebrafish embryos were continuously exposed to $\mathrm{CuO}$ NPs from 4 hours postfertilization at concentrations of 50, 25, 12.5, 6.25, or $1 \mathrm{mg} / \mathrm{L}$. The expression of gstpl and cypla was examined by quantitative reverse transcription polymerase chain reaction. The expression of tumor necrosis factor alpha and superoxide dismutase 1 was examined by quantitative reverse transcription polymerase chain reaction and Western blotting. Liver development and retinal neurodifferentiation were analyzed by whole-mount in situ hybridization, hematoxylin-eosin staining, and immunohistochemistry, and a behavioral test was performed to track the movement of larvae. We show that exposure of CuO NPs at low doses has little effect on embryonic development. However, exposure to $\mathrm{CuO}$ NPs at concentrations of $12.5 \mathrm{mg} / \mathrm{L}$ or higher leads to abnormal phenotypes and induces an inflammatory response in a dose-dependent pattern. Moreover, exposure to $\mathrm{CuO}$ NPs at high doses results in an underdeveloped liver and a delay in retinal neurodifferentiation accompanied by reduced locomotor ability. Our data demonstrate that short-term exposure to $\mathrm{CuO}$ NPs at high doses shows hepatotoxicity and neurotoxicity in zebrafish embryos and larvae.
\end{abstract}

Keywords: copper oxide nanoparticles, biotoxicity, liver, neuronal differentiation, zebrafish, oxidative stress, behavior

\section{Introduction}

In recent years, copper oxide nanoparticles ( $\mathrm{CuO}$ NPs) have been used for a variety of purposes in a wide range of commercially available products such as electric conductors, electronic chips, heat transfer nanofluids, catalysts, gas sensors, solar cells, lithium batteries, and antimicrobial agents. ${ }^{1,2}$ The massive increase in the manufacture and use of $\mathrm{CuO}$ NPs has attracted major attention regarding potentially harmful effects. In vitro studies indicate that $\mathrm{CuO}$ NPs cause genotoxicity and cytotoxicity in lung epithelial, skin, peripheral blood, and cancer cell lines. ${ }^{3-6}$ In vivo studies also reported the potential genotoxic risk of $\mathrm{CuO}$ NPs, such as increased neoplastic lesions, point mutations, DNA alterations, and DNA strand breaks. ${ }^{7,8}$ Some CuO NPs eventually enter the aquatic systems, raising concerns about toxicity from aqueous exposure.

The zebrafish (Danio rerio) is rapidly becoming an ideal model organism for evaluating the biotoxicity of a variety of nanomaterials. The ideal features of this organism include external fertilization, large number of spawn, transparent embryos, and rapid development. ${ }^{9,10}$ The liver, a main target for nanomaterial toxicity, is an essential organ 
that plays a number of vital functions including processing nutrients from ingested food, maintaining metabolites in the blood, and serving as a site for detoxification. ${ }^{11}$ The bloodbrain barrier (BBB) is a highly selective permeability barrier that separates circulating blood from brain extracellular fluid in the central nervous system (CNS). The BBB allows the passage of water, some gases, and lipid-soluble molecules by passive diffusion, as well as the selective transport of molecules such as glucose and amino acids that are crucial to neural functions. Most molecules cannot cross this barrier. However, nanoparticles are small in size and can cross the $\mathrm{BBB}$ or enter the brain through the nerve endings of the olfactory bulb, which makes the brain a target for these particles. ${ }^{12,13}$ A previous study reported that $\mathrm{CuO}$ NPs exposure induced oxidative stress and showed teratogenicity in zebrafish embryos. ${ }^{14}$ To our knowledge, the effects of $\mathrm{CuO}$ NPs on zebrafish liver development and neurodifferentiation are still uncharacterized.

To investigate the effects of exposure to $\mathrm{CuO}$ NPs in vivo, embryonic and larval zebrafish were used as an animal model in this study. Specifically, we determined the following properties: 1) characterization of $\mathrm{CuO}$ NPs and their distribution on zebrafish chorion; 2) the impact of $\mathrm{CuO}$ NP exposure on zebrafish gross development, detoxifying enzymes, and inflammatory response; and 3) the relationships between high-dose $\mathrm{CuO}$ NP exposure and liver development, retinal neurodifferentiation, and behavioral changes. Our study might help to further evaluate the short-term effects of $\mathrm{CuO}$ NPs on zebrafish development as well as the hepatotoxicity and neurotoxicity of these nanoparticles.

\section{Materials and methods Dispersion and characterization of the CuO NPs}

Commercial CuO NPs (surface area $29 \mathrm{~m}^{2} / \mathrm{g}$ ) were purchased from Sigma-Aldrich (544868; Sigma-Aldrich, St Louis, MO, USA). Fourier transform infrared (FTIR) spectrum was recorded with the Tensor 27 Fourier transform infrared spectrometer (Bruker Optik GmbH, Ettlingen, Germany) with a resolution of $2 \mathrm{~cm}^{-1}$ at $4,000-400 \mathrm{~cm}^{-1}$. The pore and particles on the chorion were tested using scanning electron microscopy (SEM) (SU8010; Hitachi Ltd., Tokyo, Japan). Briefly, embryos were exposed to $\mathrm{CuO}$ NPs at a concentration of $12.5 \mathrm{mg} / \mathrm{L}$ for 4 hours and fixed using $2.5 \%$ glutaraldehyde in phosphate-buffered saline $(\mathrm{pH} 7.2)$ overnight at $4^{\circ} \mathrm{C}$. They were subsequently washed with $30 \%, 50 \%, 80 \%, 90 \%$, and $100 \%$ (twice) ethanol and lyophilized prior to SEM imaging. The size of the particles was tested using transmission electron microscopy (TEM) (T-20; Philips, Eindhoven, the Netherlands). The CuO NPs were suspended in ultrapure water (Promega, Madison, WI, USA) at a concentration of $500 \mathrm{mg} / \mathrm{L}$ as a stock solution. The stock solution was dispersed with an ultrasonic vibrator (KQ2200; Kunshan Ultrasonic Instruments Co. Ltd., Kunshan, People's Republic of China) for 30 minutes, after which the suspension was diluted in $1 \times$ Holt buffer $(60 \mathrm{mmol} / \mathrm{L} \mathrm{NaCl}, 0.67 \mathrm{mmol} / \mathrm{L}$ $\mathrm{KCl}, 0.3 \mathrm{mmol} / \mathrm{L} \mathrm{NaHCO}_{3}, 0.9 \mathrm{mmol} / \mathrm{L} \mathrm{CaCl}_{2}, \mathrm{pH} 7.2$ ) to working concentrations of $50,25,12.5,6.25$, or $1 \mathrm{mg} / \mathrm{L}$.

\section{Experimental animals}

Wild-type zebrafish (AB strain) was used in this study and raised at $28.5^{\circ} \mathrm{C}$ with a $10 / 14$-hour dark/light cycle. ${ }^{15}$ Embryos were collected after natural spawning, sorted to remove feces and unfertilized eggs, incubated in E3 medium ( $5 \mathrm{mmol} / \mathrm{L} \mathrm{NaCl}, 0.17 \mathrm{mmol} / \mathrm{L} \mathrm{KCl}, 0.33 \mathrm{mmol} / \mathrm{L} \mathrm{CaCl}_{2}$, $0.33 \mathrm{mmol} / \mathrm{L} \mathrm{MgSO}_{4}, \mathrm{pH} 7.2$ ) at $28.5^{\circ} \mathrm{C}$, and developmentally staged by hours postfertilization (hpf) or days postfertilization (dpf). All of the procedures involving animals were approved by the Institutional Animal Care Committee at Nankai University.

\section{Aqueous exposure}

Aqueous exposure to $\mathrm{CuO}$ NPs was performed according to Organization for Economic Co-operation and Development guidelines. ${ }^{16}$ At 4 hpf, dead embryos were removed and the remaining embryos were placed into six-well plates with 30 embryos in each well. Five groups of embryos, the exposed groups, were treated continuously with $\mathrm{CuO}$ NPHolt buffer at concentrations of 50, 25, 12.5, 6.25, or $1 \mathrm{mg} / \mathrm{L}$. The same number of embryos was incubated only in Holt buffer as a control. The aqueous exposure described earlier was repeated three times.

\section{In situ hybridization}

Embryos and larvae were raised in 0.003\% 1-phenyl-2thiourea (Sigma-Aldrich Co., St Louis, MO, USA) no later than 24 hpf to prevent pigmentation, until 96 hpf. Embryos and larvae were anesthetized with $0.1 \%$ ethyl 3-aminobenzoate methanesulfonate salt (MS-222, Sigma), euthanized immediately, and fixed in 4\% paraformaldehyde at 48, 72, and $96 \mathrm{hpf}$, respectively. Whole-mount in situ hybridization was performed using a standard protocol. ${ }^{17,18}$ A ceruloplasmin (cp, GenBank NM_131802) probe was used to label the hepatocytes. The cDNA encoding $c p$ was linearized with SacI, and a riboprobe was synthesized with $\mathrm{T} 7$ polymerase. The probe was added to Eppendorf tubes at a concentration of $5 \mathrm{ng} / \mu \mathrm{L}$ and hybridized overnight at $55^{\circ} \mathrm{C}$. On the second day, the embryos were washed and incubated in an alkaline 
phosphatase-conjugated antibody (Hoffman-La Roche Ltd., Basel, Switzerland) at a dilution of 1:1,500. On the third day, nitroblue tetrazolium/5-bromo-4-chloro-3-indolyl phosphate (Roche Diagnostics) was used as an enzymatic substrate. In each group, ten animals were processed at each time point.

\section{Quantitative reverse transcription polymerase chain reaction}

Each total RNA was extracted from five embryos at $72 \mathrm{hpf}$ using Trizol according to the manufacturer's protocol (Thermo Fisher Scientific, Waltham, MA, USA) and was reverse-transcribed by Moloney Murine Leukemia Virus reverse transcriptase (Promega) using oligo (dT) primers. Quantitative reverse transcription polymerase chain reaction (qRT-PCR) was performed using the SYBR Green Labeling System (Promega). Reaction procedures included a denaturing step at $95^{\circ} \mathrm{C}$ for 5 minutes, followed by 40 cycles of $95^{\circ} \mathrm{C}$ for 15 seconds, $55^{\circ} \mathrm{C}$ for 20 seconds, and $72^{\circ} \mathrm{C}$ for 30 seconds. Primer sequences included the following: glutathione $S$-transferase (GST) pi 1 (gstp1, GenBank NM_131734), forward 5'-AAGATCATGCTGGCGGACAA-3', reverse 5'-TCACGTCAATGAGGGAAGCC'; cytochrome P450 1A (cypla, GenBank NM_131879), forward 5'-GCGTCCTGTTGTCGTACTCA-3', reverse 5'-CCAGAC TCCGACTTGATCCG-3'; tumor necrosis factor alpha (tnf $\alpha$, GenBank NM_212859), forward 5'-GAACA ACCCAGCAAACTC-3', reverse 5'-CATCACCAGC GGTAAAGG-3'; superoxide dismutase $1(\operatorname{sod} 1$, GenBank NM_131294), forward 5'-ATCAAGAGGGTGA AAAGAAGC-3', reverse 5'-AAAGCATGG ACGTGGAAAC-3'; and actin, forward 5'-TTCAC CACCACAGCCGAAAGA-3', reverse 5'-TACCGC AAGATTCCATACCCA-3'. The qRT-PCR analysis described earlier was repeated three times.

\section{Western blot analysis}

Western blotting was performed to test the expression of SOD1 and TNF $\alpha$ proteins. At $72 \mathrm{hpf}, 30$ embryos were lysed in a buffer containing protease inhibitor (Sigma), and protein concentration was quantified using a bicinchoninic acid Protein Assay Kit (EMD Millipore, Billerica, MA, USA). Proteins were separated in $10 \%$ sodium dodecyl sulfatepolyacrylamide gel electrophoresis gel and were transferred to a polyvinylidene fluoride membrane (EMD Millipore). Membranes were blocked in 5\% nonfat dry milk in Trisbuffered saline and $0.05 \%$ Tween-20 for 1 hour and incubated with primary antibodies. Two primary antibodies were used in this study: anti-TNF $\alpha$ polyclonal antibody (diluted 1:200, sc-1348; Santa Cruz Biotechnology Inc., Dallas, TX, USA) and anti-SOD1 polyclonal antibody (diluted 1:500, sc-11407; Santa Cruz Biotechnology Inc.). Anti-GAPDH (diluted 1:3,000; EMD Millipore) was used as a loading control. On the second day, the blots were rinsed with Tris-buffered saline and $0.05 \%$ Tween-20 and incubated with secondary antibodies for 1 hour. The bound antibodies were detected using an enhanced chemiluminescence assay (EMD Millipore).

\section{Measurement of SOD activity}

Thirty embryos from each group $(12.5 \mathrm{mg} / \mathrm{L}$ unexposed and $50 \mathrm{mg} / \mathrm{L}$ exposed) were collected at $72 \mathrm{hpf}$. Protein samples were prepared and quantified as described in the section "Western blot analysis". SOD activity was determined by xanthine/xanthine oxidase method using a Total Superoxide Dismutase Assay Kit (WST-8, S0101; Beyotime, Shanghai, People's Republic of China) and was measured according to the manufacturer's protocol. One unit of SOD activity was defined as the amount of protein that inhibited the rate of nitroblue tetrazolium reduction by $50 \% .{ }^{19}$ The SOD activity measurement described earlier was repeated three times.

\section{Histology and immunohistochemistry}

Embryos were anesthetized with MS-222 (Sigma), euthanized immediately, and fixed in 4\% paraformaldehyde. For hematoxylin and eosin (HE) staining at $4 \mathrm{dpf}$, the zebrafish was embedded in paraffin and $5 \mu \mathrm{m}$ thick sagittal sections were prepared. Sections were deparaffinized, rehydrated through graded ethanol, and stained using standard protocols. ${ }^{20,21}$ In each group, ten animals were processed. For immunofluorescence at $72 \mathrm{hpf}$, the embryos were cryoprotected with $20 \%$ sucrose in $0.1 \mathrm{~mol} / \mathrm{L}$ phosphate-buffered saline $(\mathrm{pH} 7.2)$ and frozen in optimal cutting temperature compound (Sakura Finetek, Torrance, CA, USA). Serial transverse cryosectioning at $8 \mu \mathrm{m}$ thickness was performed, and immunohistochemistry was performed as described previously. ${ }^{22,23}$ Three primary antibodies were used in this study: mouse monoclonal antibodies Zn12 (1:500), Zpr1 (1:500), and Zpr3 (1:500) for labeling ganglion cells, cones, and rods, respectively. All of these antibodies were from the Zebrafish International Resource Center (University of Oregon, Eugene, OR, USA). Ten animals were processed in each group.

\section{Behavioral analysis}

Larvae were divided into three groups: unexposed larvae (control group), larvae exposed to $12.5 \mathrm{mg} / \mathrm{L} \mathrm{CuO} \mathrm{NP}$ (12.5 mg/L exposed group), and larvae exposed to $50 \mathrm{mg} / \mathrm{L}$ $\mathrm{CuONP}(50 \mathrm{mg} / \mathrm{L}$ exposed group). Larvae from the $12.5 \mathrm{mg} / \mathrm{L}$ exposed group and $50 \mathrm{mg} / \mathrm{L}$ exposed group were incubated in $\mathrm{CuO}$ NP-Holt buffer until 6 dpf. Larvae from the unexposed 
group were incubated in Holt buffer until 6 dpf. At 9 am of $5 \mathrm{dpf}$ and $6 \mathrm{dpf}$, larvae were provided a 30-minute interval in E3 medium and fed with paramecia before being replaced in the $\mathrm{CuO}$ NP-Holt buffer. Behavioral test was performed at 6 dpf. Larvae from each group were collected, cleaned in E3 medium, and placed in 24-well plates. Each well contained $2 \mathrm{~mL}$ of E3 medium and one larva; six larvae were in each group. After a 15-minute acclimation period, the larvae were allowed to freely explore the aquarium. A camera positioned above the plate was used to track movement for 10 minutes. The Ethovision XT software (Noldus Information Technology, Wageningen, the Netherlands) was used to analyze the digital tracks and produce heat maps. The system noise was filtered out at a minimum movement distance of $0.2 \mathrm{~mm} .{ }^{17}$ Six parameters, including total movement distance, velocity, angular velocity, fast movement time, medium movement time, and slow movement time, were analyzed. The behavioral test described earlier was repeated three times.

\section{Photography and image analysis}

Images of the embryos and larvae were captured with a DP72 digital camera mounted on an SZX16 dissecting microscope (Olympus Corporation, Tokyo, Japan). Images of the HE staining were photographed with a DP71 digital camera mounted on a BX51 fluorescence microscope (Olympus Corporation). Images of the immunofluorescence were captured with an FV 1000 confocal microscope (Olympus Corporation). All of the resulting images were compiled in Adobe Photoshop 7.0 (Adobe Systems Incorporated, San Jose, CA, USA) and resized. They were occasionally modified for contrast and brightness using the ImageAdjustments-Contrast-Brightness setting. All of the images within an experiment were manipulated similarly.

\section{Statistical analysis}

Statistical analysis was performed with GraphPad software (version 5.0; GraphPad Software, Inc., La Jolla, CA, USA). The survival rate and hatching rate of the $\mathrm{CuO}$ NP-exposed groups and the unexposed group were represented as the average percentage of the survival and hatching rate from three repeated tests. The comparison among six groups was based on one-way analysis of variance (ANOVA). ImageJ software (1.49×; NIH, http://rsb.info.nih.gov/ij/) was used to convert the Western blot gel images to 8-bit grayscale prior to densitometric analysis of each band. ImageJ was also used to convert the immunostaining images to 8-bit grayscale prior to thresholding, positive staining, and assessing the positive area in each image. Excel was used to calculate the relative expression of gstp 1, cyp la, thf $\alpha$, or sod1 mRNA and protein, SOD activity, the relative expression of Zn12, Zpr1, and Zpr3, and parameters of behavioral test from the unexposed group, the $12.5 \mathrm{mg} / \mathrm{L}$ exposed group, and the $50 \mathrm{mg} / \mathrm{L}$ exposed group. The values were averaged across three groups, and statistical analysis was performed with a one-way ANOVA. The significance level was set at $P$-value $<0.05$.

\section{Results \\ Characterization of $\mathrm{CuO}$ NPs}

FTIR spectroscopy indicated that the peak at $522 \mathrm{~cm}^{-1}$ came from $\mathrm{Cu}-\mathrm{O}$ in the FTIR spectrum (see ${ }^{24}$; Figure 1A, arrow). SEM images showed that the pore on the surface of the chorion was $\sim 600 \mathrm{~nm}$ in diameter (Figure 1B, asterisk), which was much larger than the nanoparticles (Figure 1B, arrowheads) we used in this study. In the TEM images, $\mathrm{CuO}$ NPs exhibited different shapes and diameters. Small particles were spherical, whereas the larger ones were of irregular shapes (Figure 1C and D). The size of the $\mathrm{CuO}$ NPs was distributed from 20 to $130 \mathrm{~nm}$. Most particles had an average diameter of 50-60 nm (Figure 1E).

\section{Embryos exposed to CuO NPs at high doses showed abnormal phenotypes}

Phenotypes were assessed at 24, 48, and $72 \mathrm{hpf}$. Compared to the unexposed embryos (Figure 2A-C), no apparent malformation was observed at any time point in embryos from the $1 \mathrm{mg} / \mathrm{L}$ exposed and $6.25 \mathrm{mg} / \mathrm{L}$ exposed groups (Nusslein-Volhard and Dahm ${ }^{25}$; Figure 2D-I). However, differences were found in the gross appearance of embryos from the 12.5, 25, and $50 \mathrm{mg} / \mathrm{L}$ exposed groups. At $24 \mathrm{hpf}$, embryos had not reached the primula 5 stage, and the rudiments of the primary organs were hardly recognizable. At 48 and 72 hpf, the embryos had a shorter body axis, less pigmentation, and smaller eyes with remarkably larger yolk sacs. As the concentration of $\mathrm{CuO}$ NPs increased, the more obvious abnormal phenotypes also increased (Figure 2J-R). To evaluate the toxicity of $\mathrm{CuO}$ NPs, we further monitored the survival and hatching rate at 24, 48, and $72 \mathrm{hpf}$. For the survival rate, all exposed groups showed lower survival rates at 24, 48, and $72 \mathrm{hpf}$ (Figure 2S; ANOVA, $* P<0.05)$. At $72 \mathrm{hpf}$, the hatching rates in the $6.25,12.5,25$, and $50 \mathrm{mg} / \mathrm{L}$ exposed groups were statistically lower than those in the unexposed and $1 \mathrm{mg} / \mathrm{L}$ exposed groups (Figure 2T; ANOVA, $\left.{ }^{*} P<0.05\right)$. Together, the gross appearance, survival rate, and hatching rate results indicate that an exposure to $\mathrm{CuO}$ NPs affected embryonic development in a dose-dependent 

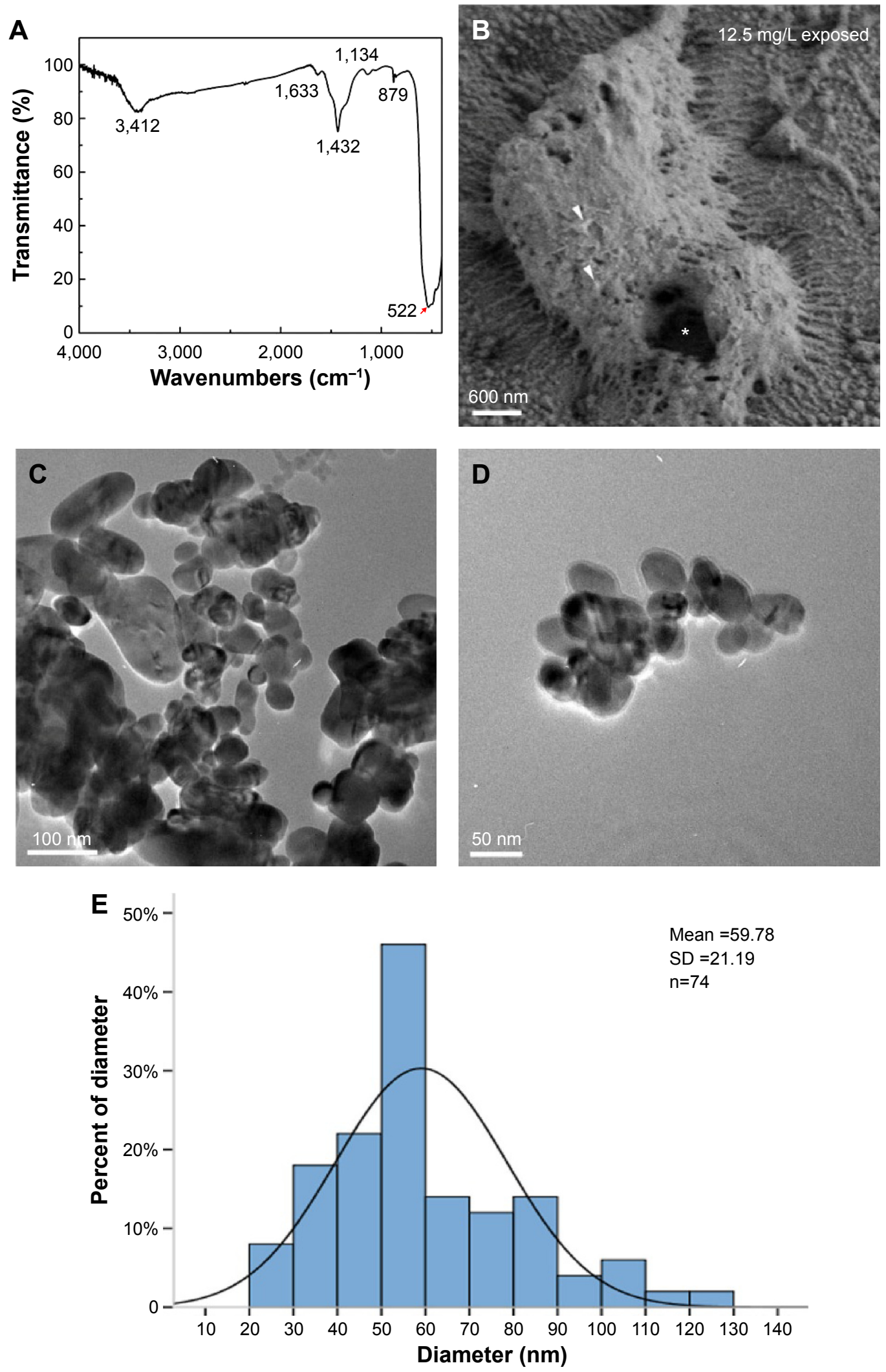

Figure I Dispersion and characterization of CuO NPs.

Notes: (A) Fourier transform infrared spectra of CuO NPs. (B) Scanning electron microscopy image of chorion surface in $12.5 \mathrm{mg} / \mathrm{L}$ exposed embryos at 8 hours postfertilization. Note that the diameter of pores (asterisk) is $\sim 600 \mathrm{~nm}$, which is much larger than that of the CuO NPs (arrowheads). (C and D) Transmission electron microscopy images of the CuO NPs. (E) Size distribution of CuO NPs. Note that most particles were 50-60 nm in diameter. Scale bar: (B), $600 \mathrm{~nm}$; (C), $100 \mathrm{~nm}$; (D), $50 \mathrm{~nm}$. Abbreviations: $\mathrm{CuO}$ NPs, copper oxide nanoparticles; SD, standard deviation. 
24 hpf
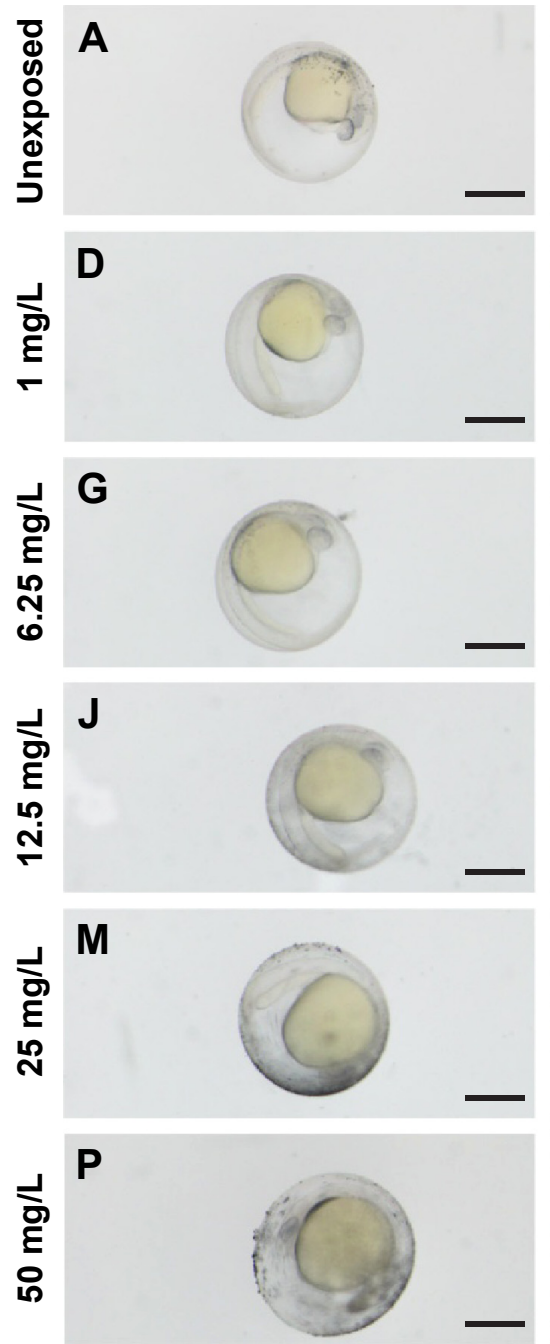

$48 \mathrm{hpf}$
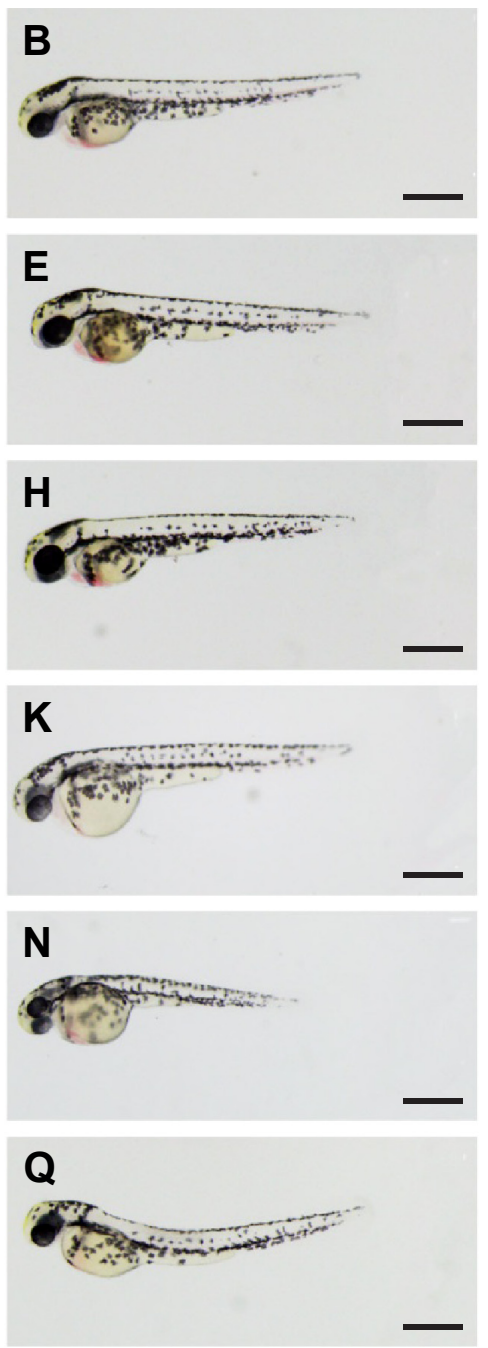

$72 \mathrm{hpf}$
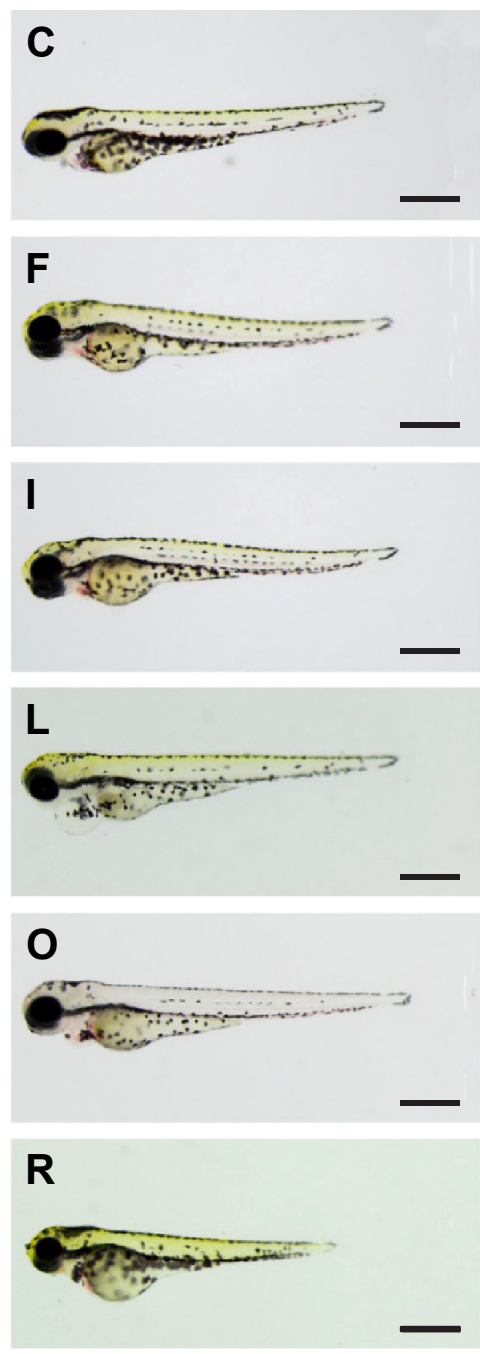

\section{$\mathbf{S}$}

S

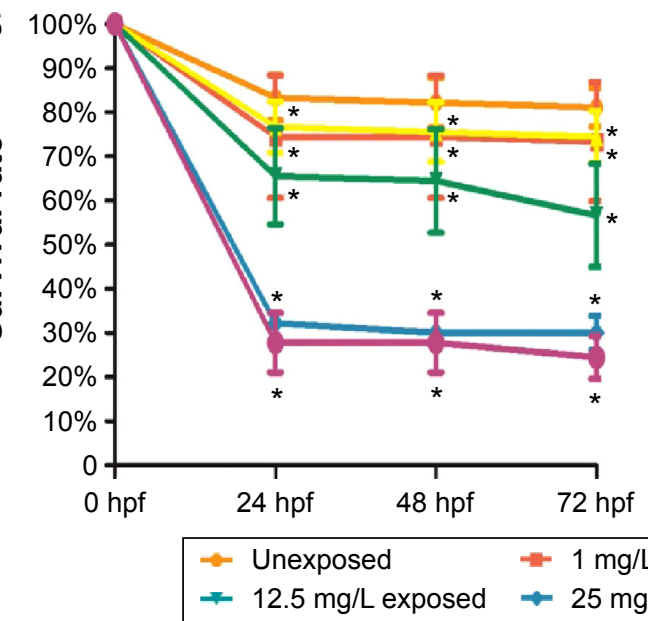

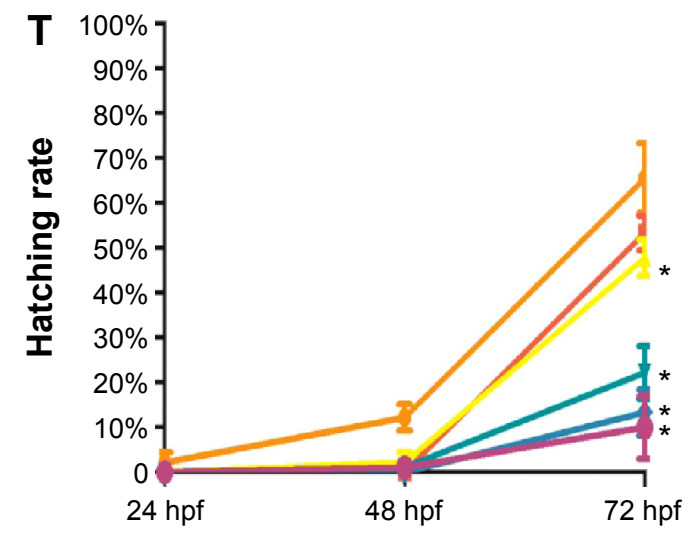

Figure 2 Phenotypes, survival rate, and hatching rate of embryos following aqueous exposure to copper oxide nanoparticles.

Notes: (A-R) Phenotypes of embryos from 24 to $72 \mathrm{hpf}$ in the unexposed group (A-C) and copper oxide nanoparticle-exposed groups at concentrations of (D-F) I mg/L, (G-I) $6.25 \mathrm{mg} / \mathrm{L},(\mathbf{J}-\mathbf{L}) 12.5 \mathrm{mg} / \mathrm{L}$, (M-O) $25 \mathrm{mg} / \mathrm{L}$, or (P-R) $50 \mathrm{mg} / \mathrm{L}$. Note that embryos in the 12.5 , 25, and $50 \mathrm{mg} / \mathrm{L}$ exposed groups have a shorter body axis, decreased pigmentation, smaller eyes, and larger yolk sacs. ( $\mathbf{S}$ and $\mathbf{T})$ Statistical analysis of the average survival rate and hatching rate. (S) Note that embryos in the exposed groups have significantly lower survival rate at 24,48 , and $72 \mathrm{hpf}$ (analysis of variance, $* \mathrm{P}<0.05$ ). (T) The hatching rates in the $6.25 \mathrm{mg} / \mathrm{L}$ or higher groups were statistically lower than those in the unexposed and I mg/L exposed groups at $72 \mathrm{hpf}$ (analysis of variance, $* P<0.05)$. Dorsal is up and rostral is left in $(\mathbf{A}-\mathbf{R})$. Scale bar in $(\mathbf{A}-\mathbf{R})$ : $500 \mu \mathrm{m}$. Abbreviation: hpf, hours postfertilization. 
manner. At high doses (12.5 mg/L or above), exposure to $\mathrm{CuO}$ NPs led to a delay in gross development. We chose 12.5 and 50 $\mathrm{mg} / \mathrm{L}$ as the two aqueous exposure doses to further investigate liver development, neurodifferentiation, and behavioral changes caused by exposure to $\mathrm{CuO}$ NPs.

\section{Exposure to $\mathrm{CuO}$ NPs at high doses increased the expression of detoxifying enzymes and induced an inflammatory response}

Xenobiotics-metabolizing enzymes play central roles in the metabolism and/or detoxification of xenobiotics. ${ }^{26}$ In this study, two enzymes, gstpl and cypla, were quantified by quantitative polymerase chain reaction following $\mathrm{CuO}$ NPs exposure. gstp1 expression was increased significantly in $12.5 \mathrm{mg} / \mathrm{L}$ exposed and $50 \mathrm{mg} / \mathrm{L}$ exposed groups (Figure 3A; ANOVA, $* P<0.05)$. The expression of cypla was slightly increased in 12.5 and $25 \mathrm{mg} / \mathrm{L}$ exposed embryos. In $50 \mathrm{mg} / \mathrm{L}$ exposed embryos, the expression of cypla was significantly higher than in other groups (Figure 3B; ANOVA, ${ }^{*} P<0.05$ ). To investigate the possible mechanisms of $\mathrm{CuO}$ NP exposure, we performed quantitative polymerase chain reaction to examine the expression of $t n f \alpha$ and sod 1 using total RNA isolated from $72 \mathrm{hpf}$ unexposed, $12.5 \mathrm{mg} / \mathrm{L}$ exposed, and $50 \mathrm{mg} / \mathrm{L}$ exposed embryos. The expression of $\operatorname{tnf} \alpha$ showed an increase in the two exposed groups, whereas the expression of sodl was decreased. However, the differences were not statistically significant (Figure 3C and D; ANOVA, $P>0.05$ ). Next, we tested TNF $\alpha$ and SOD1 protein expression using Western blotting. The expression level of TNF $\alpha$ was higher in the $12.5 \mathrm{mg} / \mathrm{L}$ exposed and $50 \mathrm{mg} / \mathrm{L}$ exposed groups than in the unexposed group (Figure 3E and F). The expression of SOD1 was similar in the unexposed and $12.5 \mathrm{mg} / \mathrm{L}$ exposed embryos, but dramatically decreased in the $50 \mathrm{mg} / \mathrm{L}$ exposed embryos (Figure 3E and G). To determine whether this decrease was functional, we measured SOD activity. When the concentration of CuO NPs was increased, SOD activity decreased. Moreover, SOD activity was significantly lower in the $50 \mathrm{mg} / \mathrm{L}$ exposed group than in the unexposed and $12.5 \mathrm{mg} / \mathrm{L}$ exposed groups (Figure $3 \mathrm{H}$; ANOVA, $* P<0.05$ ). The earlier data indicate that exposure to $\mathrm{CuO}$ NPs at higher dose activated the detoxifying enzymes, induced an inflammatory response, and stimulated oxidative stress in zebrafish embryos.

\section{Exposure to $\mathrm{CuO}$ NPs at high doses resulted in an underdeveloped liver}

Liver development was examined by whole-mount in situ hybridization using the hepatocyte-specific mRNA probe ceruloplasmin ( $c p)$ at 48, 72, and $96 \mathrm{hpf}$. At $48 \mathrm{hpf}, c p$ expression was detected on the left side of the trunk in embryos from the unexposed (Korzh et $\mathrm{al}^{27}$; Figure 4A, arrowhead), $12.5 \mathrm{mg} / \mathrm{L}$ exposed (Figure 4B, arrowhead), and $50 \mathrm{mg} / \mathrm{L}$ exposed (Figure 4C, arrowhead) groups. More $c p$-expressing cells were detected in the livers of all three groups (Figure 4D-F, arrowheads) at $72 \mathrm{hpf}$. At $96 \mathrm{hpf,} c p$ was expressed posterior to the heart and lateral to the intestine (Figure 4G-I, arrowheads). However, the size of the livers was significantly reduced in embryos or larvae from the 12.5 or $50 \mathrm{mg} / \mathrm{L}$ exposed groups at each time point (Figure 4B, C, E, F, H, and I). We performed HE staining on sections to further investigate the reduction in liver size at 96 hpf. In unexposed larva, the hepatocytes were epithelioid, polygonal-shaped cells with a central nucleus (Figure 4J and M). However, hepatocytes were irregularly shaped in the $12.5 \mathrm{mg} / \mathrm{L}$ (Figure $4 \mathrm{~K}$ and $\mathrm{N}$ ) and $50 \mathrm{mg} / \mathrm{L}$ exposed larvae (Figure $4 \mathrm{~L}$ and $\mathrm{O}$ ). The nuclei were large and darkly stained, and the cells exhibited an increased nuclear-to-cytoplasmic ratio, especially in the $50 \mathrm{mg} / \mathrm{L}$ exposed larva. These data indicate that exposure to $\mathrm{CuO}$ NPs at high doses resulted in an underdeveloped liver in embryonic and early larval zebrafish.

\section{Neuronal differentiation was delayed following $\mathrm{CuO}$ NPs exposure}

To evaluate the potential neurotoxicity of $\mathrm{CuO}$ NPs, the expression of three cell-type specific antibodies was examined. In the ganglion cell layer, the $\mathrm{Zn} 12$ antibody recognizes a cell surface epitope on ganglion cells. ${ }^{28}$ For photoreceptors in the outer nuclear layer, the Zprl antibody labels a cell surface epitope on red/green-sensitive double cones and the Zpr3 antibody labels an antigenic region on the rods. ${ }^{29-31}$ At $72 \mathrm{hpf}$, the ganglion cell layer, inner nuclear layer, and outer nuclear layer were fully laminated. Meanwhile, ganglion cells, cones, and rods were well-differentiated in the retinas of the unexposed group (Figure $5 \mathrm{~A}-\mathrm{C}$ ). Following exposure to $\mathrm{CuO}$ NPs, the retinas of the 12.5 and $50 \mathrm{mg} / \mathrm{L}$ embryos were also laminated, and the retinal neurons expressed the appropriate cell type-specific markers (Figure 5D-I). However, in retinas from both $\mathrm{CuO}$ NP exposed groups, there were fewer $\mathrm{Zn} 12$ positive, Zpr1-positive, and Zpr3-positive cells than in the retinas from the unexposed group (Figure 5J-L; ANOVA, $* P<0.05)$, which suggested that exposure to $\mathrm{CuO}$ NPs delays retinal neurodifferentiation.

\section{Exposure to $\mathrm{CuO}$ NPs at high doses resulted in reduced locomotor capacity}

To determine whether functional changes were associated with $\mathrm{CuO}$ NP exposure in zebrafish, we performed behavioral 
A

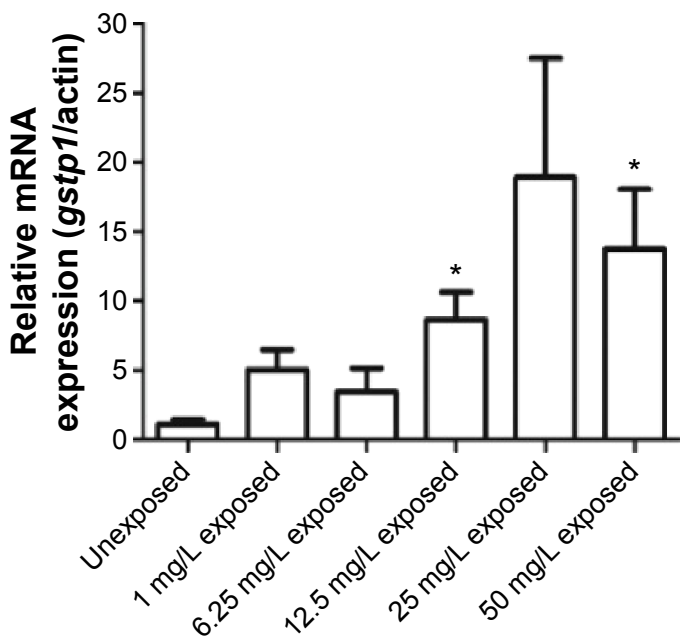

C

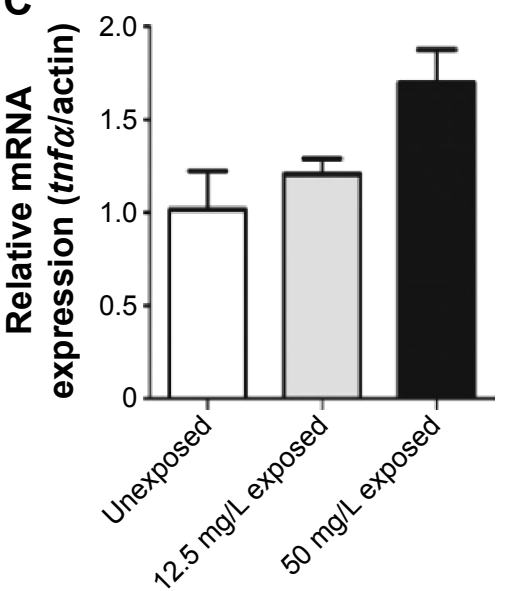

F

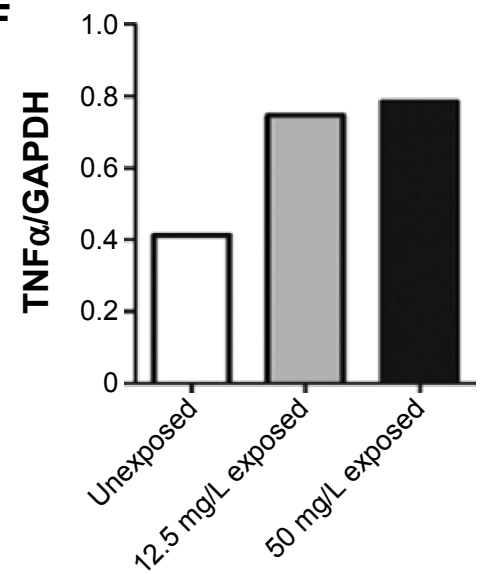

D

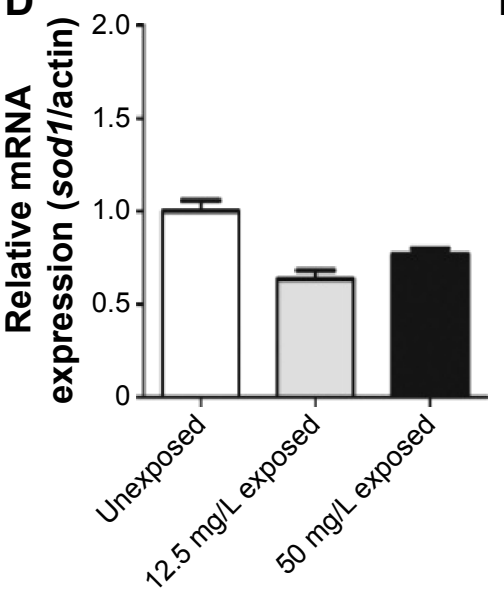

G

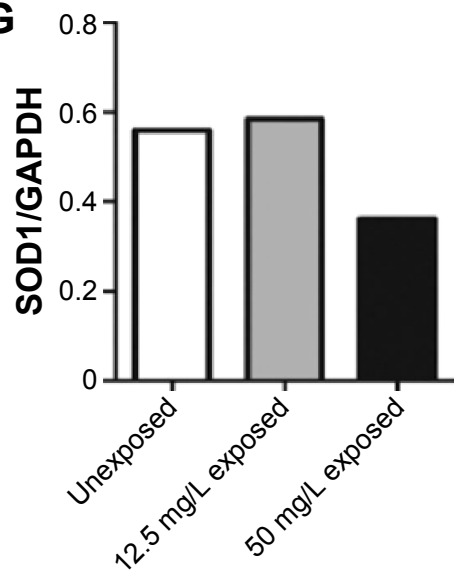

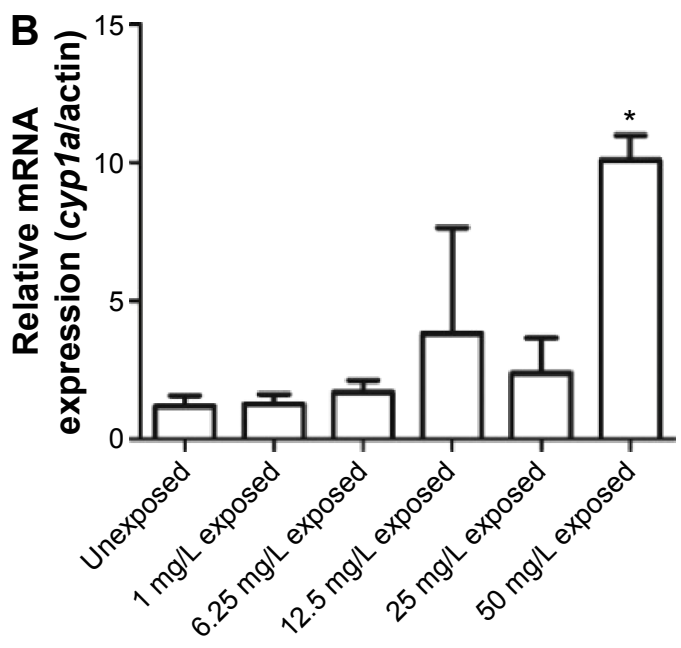

E

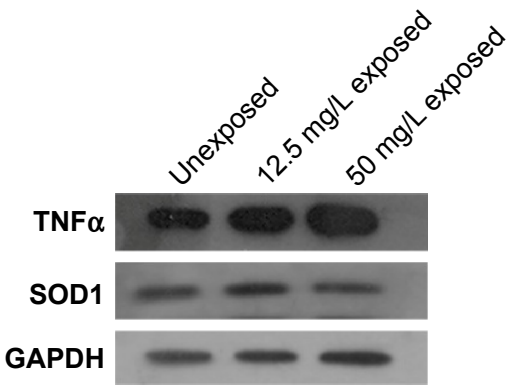

H

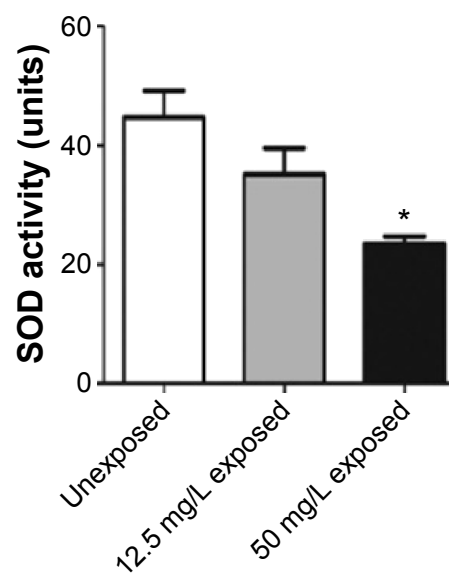

Figure 3 Expression of gstp I, cypla, tnf $\alpha$, and sodI mRNA, TNF $\alpha$ and SODI protein and measurement of SOD activity.

Notes: (A and B) Expression of gstp I and cyp/a mRNA in unexposed groups and copper oxide nanoparticle-exposed groups at concentrations of I, 6.25, I2.5, 25, or $50 \mathrm{mg} / \mathrm{L}$. (C and D) Expression of tnf $\alpha$ and sod I mRNA in the unexposed, $12.5 \mathrm{mg} / \mathrm{L}$ exposed, and $50 \mathrm{mg} / \mathrm{L}$ exposed embryos. (E) Expression of TNF $\alpha$ and SODI proteins at 72 hours postfertilization. Note that (F) TNF $\alpha$ protein expression was increased, whereas (G) SODI protein expression was decreased in the $50 \mathrm{mg} / \mathrm{L}$ exposed group. (H) The result for the SOD activity assay. Note that SOD activity significantly decreased in the $50 \mathrm{mg} / \mathrm{L}$ exposed group (analysis of variance, $* P<0.05$ ).

Abbreviations: mRNA, messenger RNA; SOD, superoxide dismutase; TNF $\alpha$, tumor necrosis factor alpha; GADPH, glyceraldehyde-3-phosphate dehydrogenase.

tests on larvae at $6 \mathrm{dpf}$. There were three groups in the trial: unexposed, exposed to $12.5 \mathrm{mg} / \mathrm{L} \mathrm{CuO} \mathrm{NPs}$ solution (12.5 mg/L exposed), and exposed to $50 \mathrm{mg} / \mathrm{L} \mathrm{CuO} \mathrm{NPs} \mathrm{solu-}$ tion $(50 \mathrm{mg} / \mathrm{L}$ exposed). After exposing the larvae to $\mathrm{CuO}$ NPs for 6 days, we performed the behavioral tests. The digital tracks and heat maps are shown in Figure 6A and B. We then analyzed the digital tracks for six parameters. Larvae from $12.5 \mathrm{mg} / \mathrm{L}$ exposed and $50 \mathrm{mg} / \mathrm{L}$ exposed groups showed decreased total movement distance, velocity, and angular velocity (Figure 6C-E; ANOVA, ${ }^{*} P<0.05$ ). No significant 

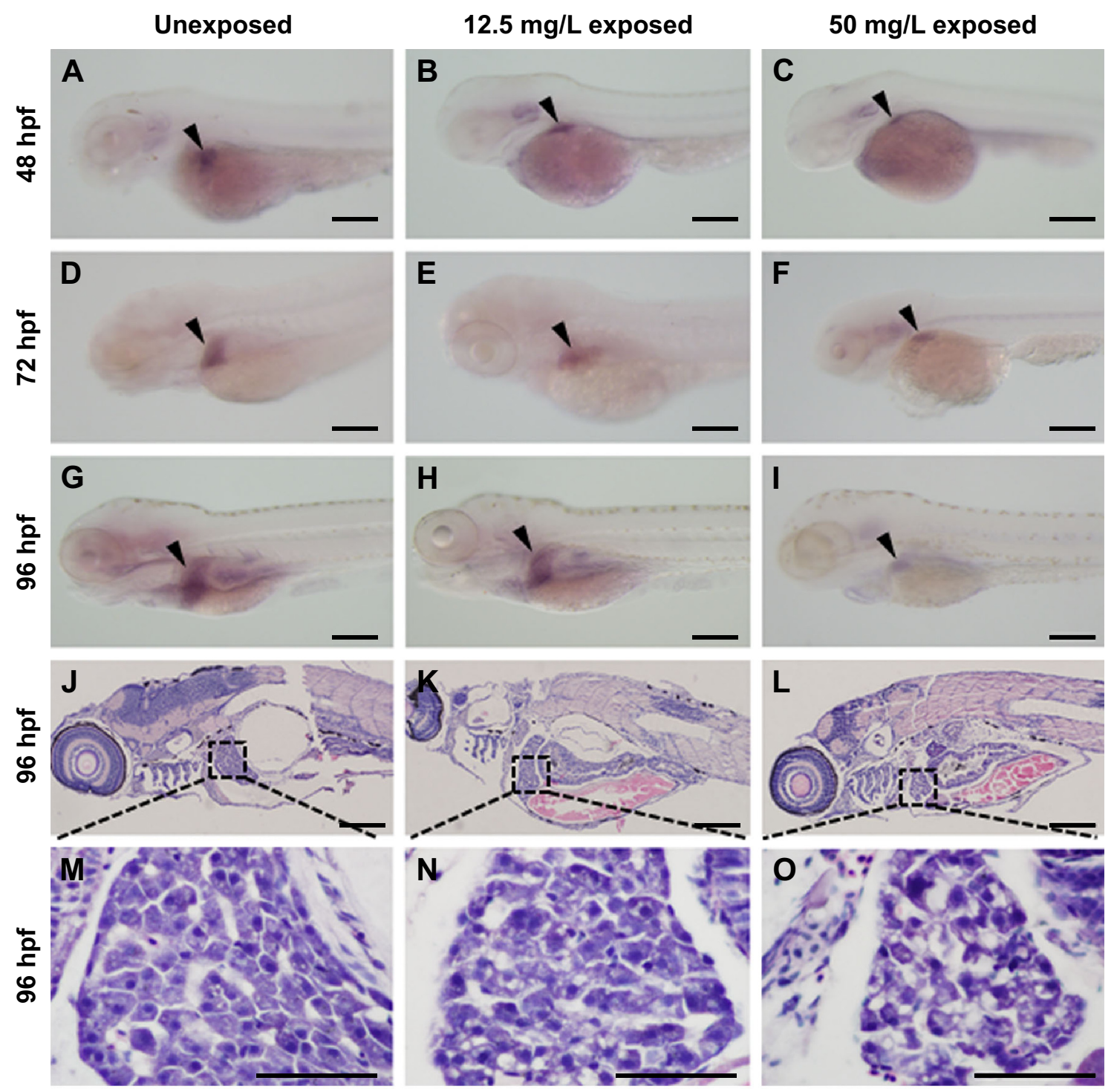

Figure 4 Liver development and hematoxylin-eosin staining of hepatocytes following aqueous exposure to copper oxide nanoparticles.

Notes: (A-I) Whole-mount in situ hybridization with the riboprobe ceruloplasmin (cp) at (A-C) 48 hpf, (D-F) 72 hpf, and (G-I) 96 hpf. Compared to the unexposed group (A, D, and G, arrowheads), the exposed embryos or larvae show livers of reduced size (B, C, E, F, H, and I, arrowheads). (J-L) Hematoxylin-eosin staining from the (J) unexposed, (K) $12.5 \mathrm{mg} / \mathrm{L}$ exposed, and (L) $50 \mathrm{mg} / \mathrm{L}$ exposed larvae at $96 \mathrm{hpf}$. (M-O) Magnified images of (J-L), respectively. Note that the hepatocytes in (N) and (O) are irregularly shaped with darkly stained nuclei. Dorsal is up and rostral is left in (A-L). Scale bar: (A-I), $200 \mu \mathrm{m} ;(\mathbf{J}-\mathbf{L}) 200 \mu \mathrm{m} ;(\mathbf{M}-\mathbf{O}), 50 \mu \mathrm{m}$.

Abbreviation: hpf, hours postfertilization.

difference was found in fast movement time among the three groups (Figure 6F). However, both the medium movement time and the slow movement time in the two exposed groups were longer than in the unexposed group. Furthermore, in the $50 \mathrm{mg} / \mathrm{L}$ exposed group, these differences were statistically significant (Figure $6 \mathrm{G}$ and $\mathrm{H}$; ANOVA, ${ }^{*} P<0.05$ ), thus revealing that exposure to $\mathrm{CuO}$ NPs resulted in the reduced locomotor capacity of zebrafish larvae.

\section{Discussion}

Currently, an increasing number of nanoparticles are used in various products. There is increased concern surrounding their safety in terms of worker exposure as well as for consumers and the general public because nanoparticles are smaller in size and have relatively larger surfaces compared to particles in the micrometer size. An in vitro study showed that $\mathrm{CuO}$ nanoparticles were more toxic than $\mathrm{CuO}$ microparticles because of their ability to damage mitochondria. ${ }^{32}$ In mice, the liver, kidney, and olfactory bulb were the main tissues in which nanoscale copper particles accumulated after nasal inhalation. ${ }^{33}$ In this study, we investigated the injury caused by commercial CuO NPs in a zebrafish model. The influence induced by other sizes of $\mathrm{CuO}$ NPs requires further study.

The characterization of $\mathrm{CuO}$ NPs is shown in Figure 1. The SEM images revealed that the size of the zebrafish 

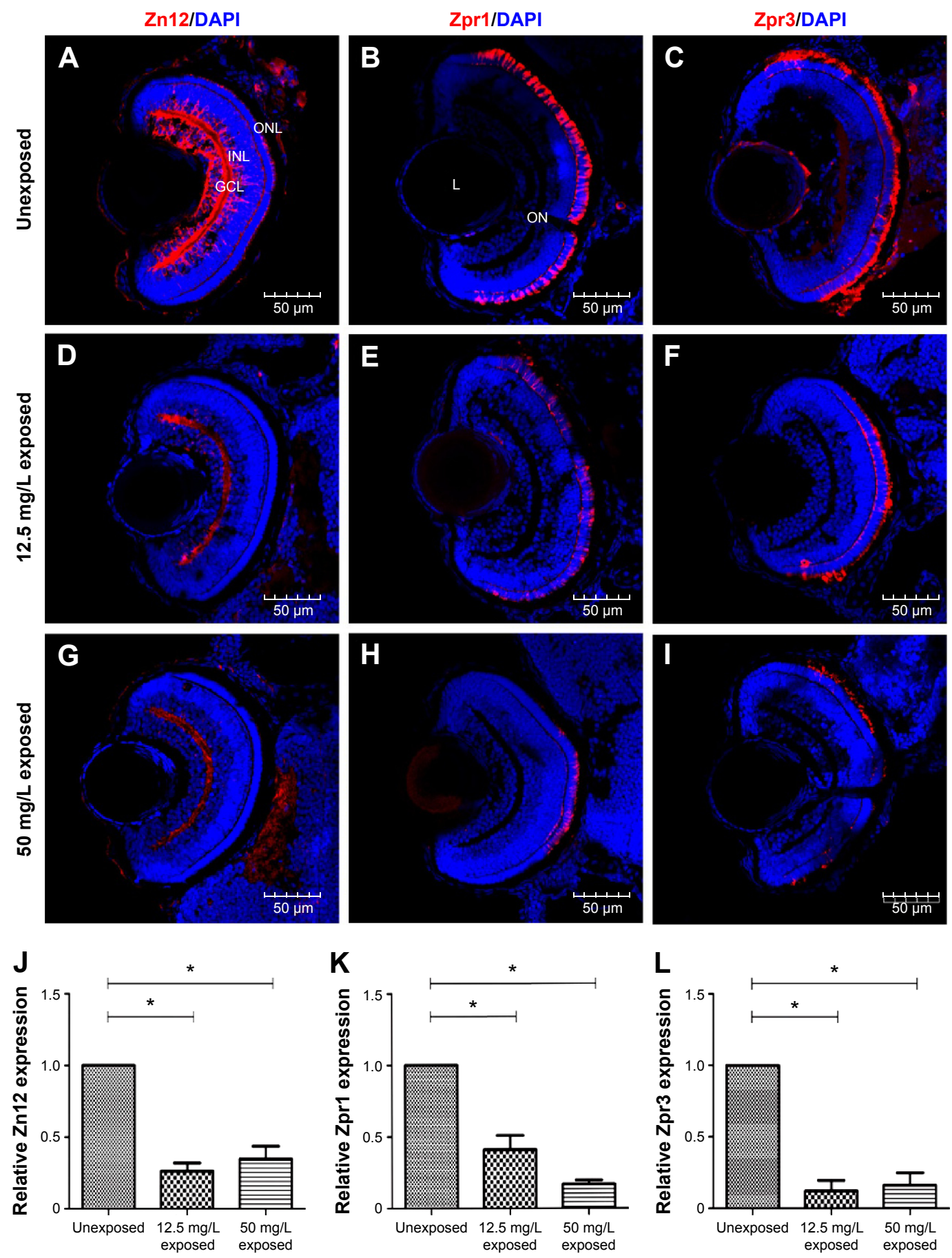

Figure 5 Neuronal differentiation in retinas following exposure to copper oxide nanoparticles.

Notes: (A-I) Sections taken through the retinas at 72 hours postfertilization. (A, D, and $\mathbf{G})$ ZnI 2 staining; (B, E, and $\mathbf{H})$ ZprI staining; and (C, F, and I) Zpr3 staining. $(\mathbf{J}-\mathbf{L})$ Note that there were fewer Zn I2-positive, Zprl-positive, and Zpr3-positive cells in treated compared to unexposed retinas. Scale bar: $(\mathbf{A}-\mathbf{I})$ : $50 \mu \mathrm{m}$. $* \mathrm{P}<0.05$. Abbreviations: DAPI, 4',6-diamidino-2-phenylindole; GCL, ganglion cell layer; INL, inner nuclear layer; L, lens; ON, optic nerve; ONL, outer nuclear layer.

chorion pore was $\sim 600 \mathrm{~nm}$ in diameter (Figure $1 \mathrm{~B}$ ). The TEM images indicated that most of the $\mathrm{CuO}$ NPs had an average diameter of 50-60 $\mathrm{nm}$. Therefore, the $\mathrm{CuO}$ NPs entered the embryos across the chorion via the pores. The toxicity of $\mathrm{CuO}$ NPs was assessed in zebrafish exposed to $\mathrm{CuO}$ NPs-Holt buffer solutions at a working concentration of 50, 25, 12.5, 6.25, or $1 \mathrm{mg} / \mathrm{L}$. The phenotypes of the embryos at concentrations of 1 and $6.25 \mathrm{mg} / \mathrm{L}$ remained similar to those of unexposed controls at 24, 48, and $72 \mathrm{hpf}$ (Figure 2D-I). Abnormal phenotypes were observed in embryos exposed to $\mathrm{CuO}$ NPs at the higher concentrations of $12.5,25$, and $50 \mathrm{mg} / \mathrm{L}$. The differences included a shorter body axis, decreased 

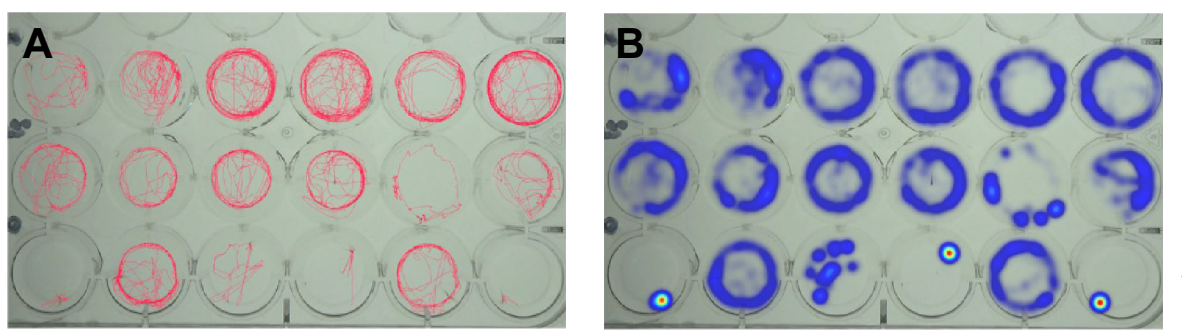

Unexposed

$12.5 \mathrm{mg} / \mathrm{L}$ exposed

$50 \mathrm{mg} / \mathrm{L}$ exposed

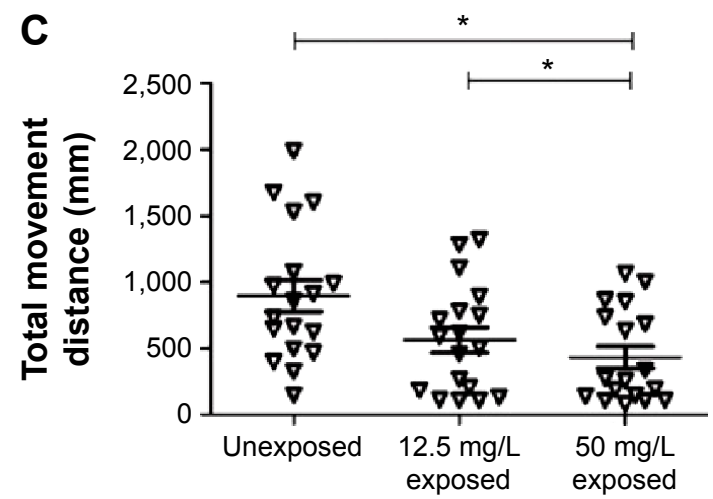

D
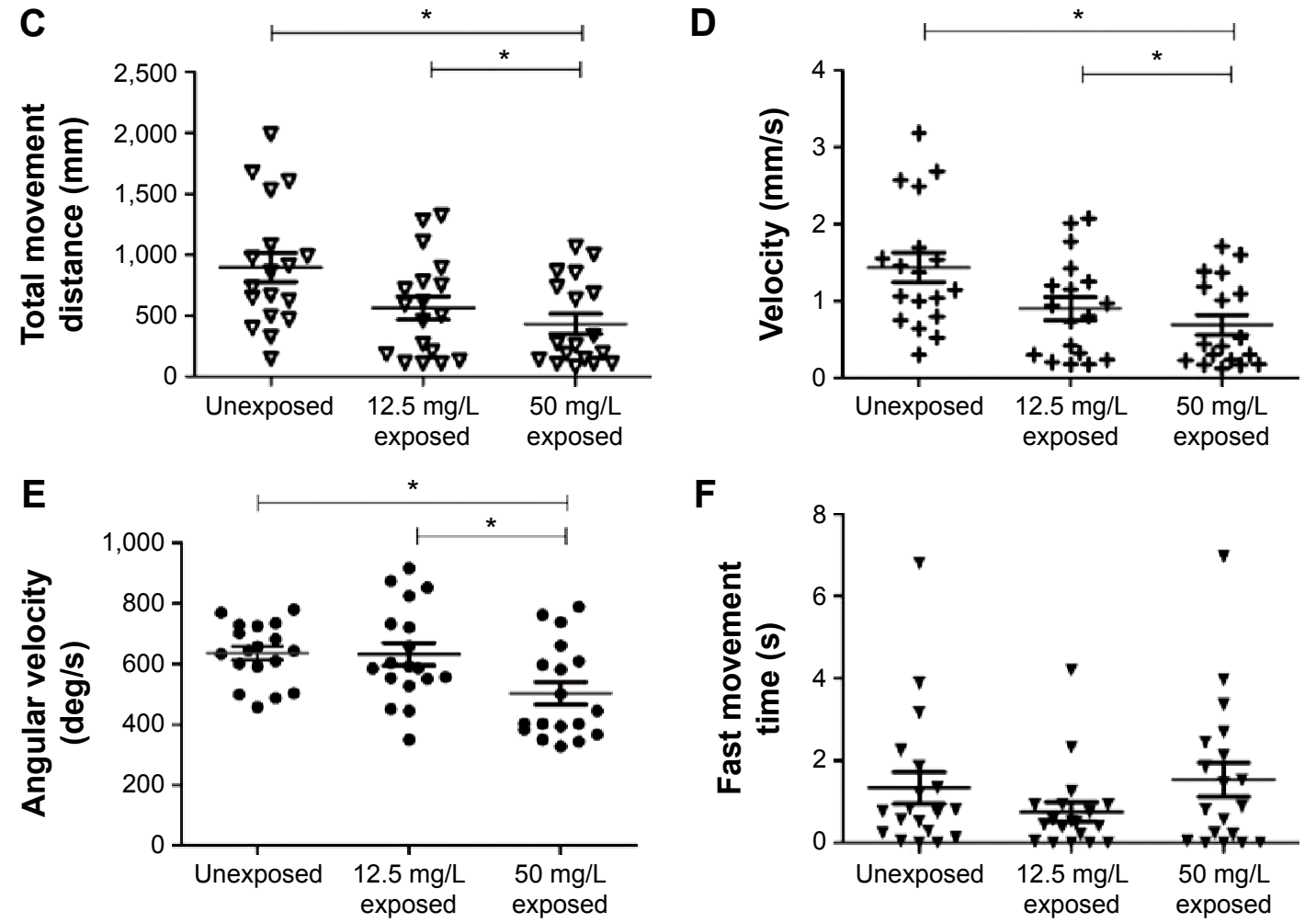

$\mathbf{F}$
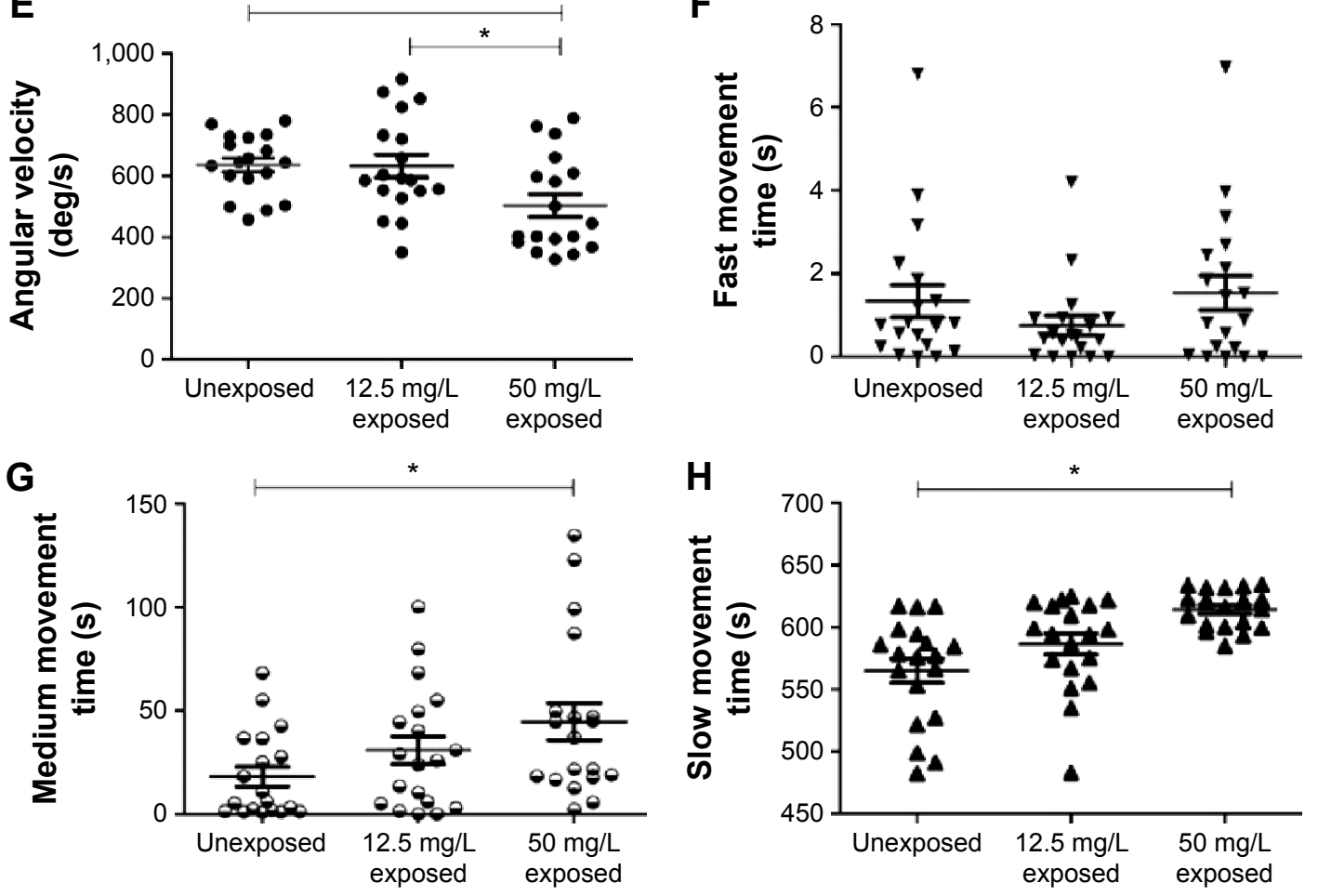

Figure 6 Reduction of locomotor capacity following exposure to copper oxide nanoparticles.

Notes: (A) Digital tracks of larvae from the unexposed, $12.5 \mathrm{mg} / \mathrm{L}$ exposed, and $50 \mathrm{mg} / \mathrm{L}$ exposed groups at 6 days postfertilization. (B) Heat maps of the digital tracks (A). (C-H) Statistical analyses on the average of the six parameters. Note that the (C) total movement distance, (D) velocity, and (E) the angular velocity in the two exposed groups are significantly lower in a dose-dependent pattern (analysis of variance, $\left.{ }^{*} \mathbf{P}<0.05\right)$. ( $\mathbf{G}$ and $\left.\mathbf{H}\right)$ The medium movement time and the slow movement time of the $50 \mathrm{mg} / \mathrm{L}$ exposed larvae were significantly longer than in the unexposed larvae (analysis of variance, $* P<0.05$ ).

Abbreviations: deg, degree; s, second.

pigmentation, smaller eyes, and remarkably bigger yolk sacs (Figure 2J-R). As the concentration of $\mathrm{CuO}$ NPs increased, the abnormal phenotypes became more severe. Additionally, there was a significant difference in the survival and hatching rate between animals exposed to $\mathrm{CuO}$ NPs and the unexposed controls (Figure $2 \mathrm{~S}$ and $\mathrm{T}$ ), which is consistent with a previous study. ${ }^{34}$ We believe that aqueous $\mathrm{CuO}$ NP exposure at concentrations of $12.5 \mathrm{mg} / \mathrm{L}$ or higher will lead to a dose-dependent disturbance in the gross development of zebrafish. Because $12.5 \mathrm{mg} / \mathrm{L}$ was the threshold for the abnormal phenotype and 
$50 \mathrm{mg} / \mathrm{L}$ was the highest concentration used in this study, we chose these two doses to further study the impact of $\mathrm{CuO}$ NPs on the liver and CNS.

The GSTs are one of the key enzymes that mediate Phase II of cellular detoxification. In zebrafish, there are two genes in GST Pi class, gstpl and gstp2. Gstpl shows high expression throughout zebrafish tissues, unlike low expression of gstp $2 .{ }^{35}$ Cytochrome P450 1a (cypla) is a member of the cytochrome P450 (cyp) mixed-function oxidase system, which is responsible for the detoxification of exogenous chemicals and the metabolism of endogenous substrates in the body. ${ }^{36}$ When CuO NPs were introduced into the embryos, especially at higher doses, gstpland cypla were activated in order to protect the body against potentially harmful impacts and to minimize the insults (Figure $3 \mathrm{~A}$ and $\mathrm{B}$ ). TNF $\alpha$, a pleiotropic inflammatory cytokine produced mainly by activated macrophages, mediates a broad range of cellular activities, including proliferation, survival, differentiation, and apoptosis, and is considered to be essential for the induction and maintenance of the inflammatory immune response. ${ }^{37}$ Both the mRNA and protein expression of TNF $\alpha$ increased in the two exposed groups (Figure 3C, E, and F). Superoxide is produced as a by-product of oxygen metabolism and causes several types of cell damage. SOD enzymes alternately catalyze the dismutation of the superoxide radical into either an ordinary molecular oxygen or hydrogen peroxide. Thus, SOD enzymes are an important antioxidant defense for nearly all cells exposed to oxygen. ${ }^{38,39}$ The expression of sod 1 mRNA and SOD1 protein was decreased in the exposed groups, accompanied by decreased SOD activity (Figure 3D, $\mathrm{E}, \mathrm{G}$, and $\mathrm{H}$ ). It has previously been shown that oxidative damage might be a common result of cell damage induced by many types of nanoparticles. ${ }^{40}$ The decline in the SOD activity directly revealed that the antioxidant system was overpowered and the embryos were under stress. ${ }^{14}$ Our results from TNF $\alpha$ and SOD1 expression experiments support our hypothesis that $\mathrm{CuO}$ NP exposure at high doses induces an inflammatory response and stimulates oxidative stress, which results in an accumulation of oxygen-derived free radicals.

Compared to the mammalian liver, the zebrafish liver has distinguishable histological characteristics. The portal veins, hepatic arteries, and large biliary ducts are distributed stochastically within the hepatic parenchyma. Hepatocytes are arranged as tubules that enclose small bile ducts. ${ }^{41}$ Despite these differences, the genes and developmental pathways are highly conserved between zebrafish and mammals. Hepatocytes make up the majority of a liver and perform most of the liver's functions including metabolism, detoxification, and homeostasis. ${ }^{42}$ In this study, we used two approaches to identify the effects of $\mathrm{CuO}$ NPs on the liver. First, liver development was studied using whole-mount in situ hybridization. $c p$ is a specific molecular marker that detects early hepatic cells and is expressed in the liver bud from 32 to $34 \mathrm{hpf}$ onward. ${ }^{43,44}$ In embryos and larvae from the 12.5 and $50 \mathrm{mg} / \mathrm{L}$ exposed groups, the cellular localization of $c p$-expressing cells was similar to that of unexposed embryos or larvae. However, the exposed embryos or larvae exhibited livers of reduced size (Figure 4B, C, E, F, H, and I). Second, we examined the morphology of livers by HE staining at $96 \mathrm{hpf}$. Under physiological conditions, the hepatocytes are epithelioid, polygonal-shaped cells with a central nucleus. ${ }^{45}$ However, hepatocytes from the 12.5 and $50 \mathrm{mg} / \mathrm{L}$ exposed larvae showed some degree of immaturity, especially in the $50 \mathrm{mg} / \mathrm{L}$ exposed larvae. The hepatocytes were in irregular shapes with large and darkly stained nuclei and an increased nuclear-to-cytoplasmic ratio (Figure 4K, L, $\mathrm{N}$, and $\mathrm{O}$ ). The consistent findings from in situ hybridization and $\mathrm{HE}$ staining demonstrated that with a higher exposure dose, the morphological changes were more obvious. The exposure to $\mathrm{CuO}$ NPs at high doses was hepatotoxic, as seen by slower liver development in zebrafish embryos.

Anatomically and developmentally, the retina is known to be an extension of the CNS and is used as an ideal model to study brain development, injury, and diseases. ${ }^{46}$ The zebrafish retina is rapidly becoming a major model for the study of neurogenesis due to its scheduled spatiotemporal developmental pattern. ${ }^{47}$ Ganglion cells are the first identifiable cells that exit the cell cycle at $\sim 28-32 \mathrm{hpf}$ and differentiation then spreads dorsally around to the ventral temporal retina in a wave-like manner. ${ }^{48}$ The cells in the outer nuclear layer, the cone and rod photoreceptors, complete development by $72 \mathrm{hpf.}{ }^{49}$ In this study, Zn12, Zpr1, and Zpr3 antibodies were used as markers to probe the differentiation of ganglion cells, cones, and rods, respectively. Although Zn12-, Zpr1-, and Zpr3-positive cells were detected at $72 \mathrm{hpf}$ in the $12.5 \mathrm{mg} / \mathrm{L}$ exposed and $50 \mathrm{mg} / \mathrm{L}$ exposed retinas as well as in unexposed controls (Figure 5A-I), the number of positive cells was significantly decreased in both $\mathrm{CuO}$ NP-exposed groups compared to the unexposed group (Figure 5J-L). Combined with the smaller eyes following exposure at a concentration of $12.5 \mathrm{mg} / \mathrm{L}$ or above, we believe that exposure to $\mathrm{CuO}$ NPs at high doses does not alter the positional information or cell identities in the retina. However, exposure to $\mathrm{CuO}$ NPs at higher concentrations leads to a delay in neuronal differentiation. Future studies on larval or adult zebrafish will be helpful to explore the neurotoxicity of $\mathrm{CuO}$ NPs in depth.

The behavioral analysis of zebrafish movement is very intuitive, simple, and quick. ${ }^{50-52}$ Until now, the behavioral 
aspects of $\mathrm{CuO}$ NP exposure have not been reported. In this study, locomotion was evaluated by determining the total movement distance, velocity, angular velocity, fast movement time, medium movement time, and slow movement time. The angular velocity represents the amount of turning per unit time. ${ }^{17}$ The total movement distance, velocity, and angular velocity decreased significantly in the exposed larvae in a dose-dependent manner (Figure 6C-E). Combined with the digital tracks and heat maps (Figure 6A and B), these results showed that larvae from the two exposed groups were less active compared with larvae from the unexposed group. Three swimming speeds, namely, slow $(<5 \mathrm{~mm} / \mathrm{s})$, medium $(5 \mathrm{~mm} / \mathrm{s} \leq \mathrm{v} \leq 20 \mathrm{~mm} / \mathrm{s})$, and fast $(>20 \mathrm{~mm} / \mathrm{s})$, described the movement trajectory of larval zebrafish. ${ }^{53}$ The medium movement time and the slow movement time were extended in the exposed groups (Figure 6G and $\mathrm{H}$ ), which indicated that most larvae preferred to swim at a middle-low speed following $\mathrm{CuO}$ NP exposure. This is the first study to demonstrate that $\mathrm{CuO}$ NP exposure at high doses results in reduced locomotion ability. The altered larval behaviors might result from the delayed development of the CNS or an impact on the neuromuscular system. ${ }^{54}$

Overall, our data indicate that $\mathrm{CuO} \mathrm{NP}$ aqueous exposure at high doses $(12.5 \mathrm{mg} / \mathrm{L}$ or above) activates xenobioticsmetabolizing enzymes, induces an inflammatory response, and shows developmental toxicity on the zebrafish liver and CNS. Further testing of long-term exposure will help us develop a thorough understanding of the environmental concerns and safe use of $\mathrm{CuO}$ NPs.

\section{Acknowledgments}

This work was supported by the Chinese National Natural Science Foundation 81301080 (YL), the Tianjin Natural Science Foundation 15JCYBJC24400 (YL) 15JCQNJC10900 (JC), and the Scientific Research Foundation for the Returned Overseas Chinese Scholars 2012-1707 (YL).

\section{Author contributions}

YL conceived and designed the experiment. YL and JC supervised the work. YS, GZ, ZH, and YW performed the experiments. YS and JC analyzed the data. YL and YS wrote the paper. All authors contributed toward data analysis, drafting and critically revising the paper and agree to be accountable for all aspects of the work.

\section{Disclosure}

The authors report no conflicts of interest in this work.

\section{References}

1. Allaker RP. The use of nanoparticles to control oral biofilm formation. $J$ Dent Res. 2010;89(11):1175-1186.

2. Bondarenko O, Juganson K, Ivask A, Kasemets K, Mortimer M, Kahru A. Toxicity of $\mathrm{Ag}, \mathrm{CuO}$ and $\mathrm{ZnO}$ nanoparticles to selected environmentally relevant test organisms and mammalian cells in vitro: a critical review. Arch Toxicol. 2013;87(7):1181-1200.

3. Alarifi S, Ali D, Verma A, Alakhtani S, Ali BA. Cytotoxicity and genotoxicity of copper oxide nanoparticles in human skin keratinocytes cells. Int J Toxicol. 2013;32(4):296-307.

4. Carmona ER, Inostroza-Blancheteau C, Obando V, Rubio L, Marcos R. Genotoxicity of copper oxide nanoparticles in Drosophila melanogaster. Mutat Res Genet Toxicol Environ Mutagen. 2015;791:1-11.

5. Semisch A, Ohle J, Witt B, Hartwig A. Cytotoxicity and genotoxicity of nano - and microparticulate copper oxide: role of solubility and intracellular bioavailability. Part Fibre Toxicol. 2014;11:10.

6. Sun T, Yan Y, Zhao Y, Guo F, Jiang C. Copper oxide nanoparticles induce autophagic cell death in A549 cells. PLoS One. 2012;7(8):e43442.

7. Song MF, Li YS, Kasai H, Kawai K. Metal nanoparticle-induced micronuclei and oxidative DNA damage in mice. J Clin Biochem Nutr. 2012;50(3):211-216.

8. Yokohira M, Hashimoto N, Yamakawa K, et al. Lung carcinogenic bioassay of $\mathrm{CuO}$ and $\mathrm{TiO}(2)$ nanoparticles with intratracheal instillation using F344 male rats. J Toxicol Pathol. 2009;22(1):71-78.

9. Gerlai R. Associative learning in zebrafish (Danio rerio). Methods Cell Biol. 2011;101:249-270.

10. Hitchcock PF, Raymond PA. The teleost retina as a model for developmental and regeneration biology. Zebrafish. 2004;1(3):257-271.

11. Cheng W, Guo L, Zhang Z, et al. HNF factors form a network to regulate liver-enriched genes in zebrafish. Dev Biol. 2006;294(2):482-496.

12. Hu YL, Gao JQ. Potential neurotoxicity of nanoparticles. Int J Pharm. 2010;394(1-2):115-121.

13. Yang Z, Liu ZW, Allaker RP, et al. A review of nanoparticle functionality and toxicity on the central nervous system. $J R$ Soc Interface. 2010; 7 Suppl 4:S411-S422.

14. Ganesan S, Anaimalai Thirumurthi N, Raghunath A, Vijayakumar S, Perumal E. Acute and sub-lethal exposure to copper oxide nanoparticles causes oxidative stress and teratogenicity in zebrafish embryos. $J$ Appl Toxicol. 2015;36(4):554-567.

15. Westerfield M. The Zebrafish Book: A Guide for the Laboratory Use of Zebrafish (Brachydanio rerio). Eugene: University of Oregon Press; 1993.

16. Buschmann J. The OECD guidelines for the testing of chemicals and pesticides. Methods Mol Biol. 2013;947:37-56.

17. Fang YW, Lei XD, Li X, et al. A novel model of demyelination and remyelination in a GFP-transgenic zebrafish. Biol Open. 2015;4(1): $62-68$.

18. Thisse C, Thisse B. High-resolution in situ hybridization to wholemount zebrafish embryos. Nat Protoc. 2008;3(1):59-69.

19. Wang L, Hao J, Hu J, et al. Protective effects of ginsenosides against Bisphenol A-induced cytotoxicity in 15P-1 Sertoli cells via extracellular signal-regulated kinase 1/2 signalling and antioxidant mechanisms. Basic Clin Pharmacol Toxicol. 2012;111(1):42-49.

20. Monette MM, Evans DL, Krunkosky T, Camus A, Jaso-Friedmann L. Nonspecific cytotoxic cell antimicrobial protein (NCAMP-1): a novel alarmin ligand identified in zebrafish. PLoS One. 2015;10(2):e0116576.

21. Sun D, Zhang Y, Wang C, Hua X, Zhang XA, Yan J. Sox9-related signaling controls zebrafish juvenile ovary-testis transformation. Cell Death Dis. 2013;4:e930.

22. Huang T, Cui J, Li L, Hitchcock PF, Li Y. The role of microglia in the neurogenesis of zebrafish retina. Biochem Biophys Res Commun. 2012; 421(2):214-220.

23. Wang YJ, He ZZ, Fang YW, et al. Effect of titanium dioxide nanoparticles on zebrafish embryos and developing retina. Int $J$ Ophthalmol. 2014;7(6):917-923.

24. Wang DJ, Guo L, Li DS, Fu F, Wang WL, Yan HT. [Study on spectroscopic properties of $\mathrm{CuO}$ nanoparticles]. Guang pu xue yu guang pu fen xi. 2008;28(4):788-792. 
25. Nusslein-Volhard C, Dahm R, editors. Zebrafish: A Practical Approach. 1st ed. Oxford: Oxford University Press; 2002.

26. Puatanachokchai R, Morimura K, Wanibuchi H, et al. Alpha-benzene hexachloride exerts hormesis in preneoplastic lesion formation of rat hepatocarcinogenesis with the possible role for hepatic detoxifying enzymes. Cancer Lett. 2006;240(1):102-113.

27. Korzh S, Emelyanov A, Korzh V. Developmental analysis of ceruloplasmin gene and liver formation in zebrafish. Mech Dev. 2001; 103(1-2):137-139.

28. Fadool JM, Dowling JE. Zebrafish: a model system for the study of eye genetics. Prog Retin Eye Res. 2008;27(1):89-110.

29. Qin Z, Barthel LK, Raymond PA. Genetic evidence for shared mechanisms of epimorphic regeneration in zebrafish. Proc Natl Acad Sci U S A. 2009;106(23):9310-9315.

30. Nelson SM, Park L, Stenkamp DL. Retinal homeobox 1 is required for retinal neurogenesis and photoreceptor differentiation in embryonic zebrafish. Dev Biol. 2009;328(1):24-39.

31. Bernardos RL, Barthel LK, Meyers JR, Raymond PA. Late-stage neuronal progenitors in the retina are radial Muller glia that function as retinal stem cells. $J$ Neurosci. 2007;27(26):7028-7040.

32. Karlsson HL, Gustafsson J, Cronholm P, Moller L. Size-dependent toxicity of metal oxide particles - a comparison between nano- and micrometer size. Toxicol Lett. 2009;188(2):112-118.

33. Liu Y, Gao Y, Zhang L, et al. Potential health impact on mice after nasal instillation of nano-sized copper particles and their translocation in mice. J Nanosci Nanotechnol. 2009;9(11):6335-6343.

34. Kovrižnych JA, Sotníková R, Zeljenková D, Rollerová E, Szabová E, Wimmerová S. Acute toxicity of 31 different nanoparticles to zebrafish (Danio rerio) tested in adulthood and in early life stages - comparative study. Interdiscip Toxicol. 2013;6(2):67-73.

35. Glisic B, Mihaljevic I, Popovic M, et al. Characterization of glutathioneS-transferases in zebrafish (Danio rerio). Aquat Toxicol. 2015;158: $50-62$.

36. Nelson DR, Zeldin DC, Hoffman SM, Maltais LJ, Wain HM, Nebert DW. Comparison of cytochrome P450 (CYP) genes from the mouse and human genomes, including nomenclature recommendations for genes, pseudogenes and alternative-splice variants. Pharmacogenetics. 2004;14(1):1-18.

37. Al-Gayyar MM, Elsherbiny NM. Contribution of TNF-alpha to the development of retinal neurodegenerative disorders. Eur Cytokine Netw. 2013;24(1):27-36.

38. Celardo I, Pedersen JZ, Traversa E, Ghibelli L. Pharmacological potential of cerium oxide nanoparticles. Nanoscale. 2011;3(4):1411-1420.

39. Nash KM, Ahmed S. Nanomedicine in the ROS-mediated pathophysiology: applications and clinical advances. Nanomed Nanotech Biol Med. 2015;11(8):2033-2040.
40. Oberdörster G, Oberdörster E, Oberdörster J. Nanotoxicology: an emerging discipline evolving from studies of ultrafine particles. Environ Health Perspect. 2005;113(7):823-839.

41. Field HA, Ober EA, Roeser T, Stainier DY. Formation of the digestive system in zebrafish. I. Liver morphogenesis. Dev Biol. 2003;253(2): 279-290.

42. Cox AG, Goessling W. The lure of zebrafish in liver research: regulation of hepatic growth in development and regeneration. Curr Opin Genet Dev. 2015;32:153-161.

43. Li Y, Farooq M, Sheng D, et al. Augmenter of liver regeneration (alr) promotes liver outgrowth during zebrafish hepatogenesis. PLoS One. 2012;7(1):e30835.

44. Qi F, Song J, Yang H, et al. Mmp23b promotes liver development and hepatocyte proliferation through the tumor necrosis factor pathway in zebrafish. Hepatology. 2010;52(6):2158-2166.

45. Holden JA, Layfield LJ, Matthews JL. The Zebrafish: Atlas of Macroscopic and Microscopic Anatomy. Cambridge: Cambridge University Press; 2012.

46. London A, Benhar I, Schwartz M. The retina as a window to the brain-from eye research to CNS disorders. Nat Rev Neurol. 2013;9(1):44-53.

47. Randlett $\mathrm{O}$, Norden $\mathrm{C}$, Harris WA. The vertebrate retina: a model for neuronal polarization in vivo. Dev Neurobiol. 2011;71(6):567-583.

48. Gramage E, D'Cruz T, Taylor S, Thummel R, Hitchcock PF. Midkine-a protein localization in the developing and adult retina of the zebrafish and its function during photoreceptor regeneration. PLoS One. 2015; 10(3):e0121789.

49. Pittman AJ, Law MY, Chien CB. Pathfinding in a large vertebrate axon tract: isotypic interactions guide retinotectal axons at multiple choice points. Development. 2008;135(17):2865-2871.

50. Deshmukh VA, Tardif V, Lyssiotis CA, et al. A regenerative approach to the treatment of multiple sclerosis. Nature. 2013;502(7471):327-332.

51. Lieschke GJ, Currie PD. Animal models of human disease: zebrafish swim into view. Nat Rev Genet. 2007;8(5):353-367.

52. Riehl R, Kyzar E, Allain A, et al. Behavioral and physiological effects of acute ketamine exposure in adult zebrafish. Neurotoxicol Teratol. 2011;33(6):658-667.

53. Winter MJ, Redfern WS, Hayfield AJ, Owen SF, Valentin JP, Hutchinson TH. Validation of a larval zebrafish locomotor assay for assessing the seizure liability of early-stage development drugs. J Pharmacol Toxicol Methods. 2008;57(3):176-187.

54. Duan J, Yu Y, Shi H, et al. Toxic effects of silica nanoparticles on zebrafish embryos and larvae. PLoS One. 2013;8(9):e74606.
International Journal of Nanomedicine

\section{Publish your work in this journal}

The International Journal of Nanomedicine is an international, peerreviewed journal focusing on the application of nanotechnology in diagnostics, therapeutics, and drug delivery systems throughout the biomedical field. This journal is indexed on PubMed Central, MedLine, CAS, SciSearch $\AA$, Current Contents ${ }^{\circledR} /$ Clinical Medicine,

\section{Dovepress}

Journal Citation Reports/Science Edition, EMBase, Scopus and the Elsevier Bibliographic databases. The manuscript management system is completely online and includes a very quick and fair peer-review system, which is all easy to use. Visit http://www.dovepress.com/ testimonials.php to read real quotes from published authors. 